Gut, 1960, 1, 294.

\title{
AN ASSESSMENT OF THE VALUE OF SERUM CHOLINESTERASE AS A LIVER FUNCTION TEST AND IN THE DIAGNOSIS OF JAUNDICE
}

\author{
BY \\ WILLIAM BURNETT
}

From the Departments of Surgery, University of Aberdeen, and Western Infirmary, Glasgow

This report assesses the value of cholinesterase (ChE) activity as an indicator of liver function and analyses its usefulness in the diagnosis of jaundice. A rapid method of determination has been used, and alterations in ChE activity in conditions other than liver disease have been studied to permit a fuller and more accurate survey of its value as a liver function test.

The level of serum cholinesterase activity remains constant under normal circumstances, and follows the pattern of protein metabolism, falling in catabolism and rising in anabolism.

In hepatocellular disease cholinesterase activity is lowered. Very low levels in cirrhosis with jaundice indicate a grave prognosis. Normal levels are usual in post-hepatic jaundice unless complicating factors are present, such as cholangitis or liver metastases.

Serum cholinesterase is useful both as a liver function test and in the diagnosis of jaundice provided consideration is given to the other factors which affect the level of activity of the enzyme.

Estimation of the level of activity of the cholinesterase (ChE) found in serum was first suggested by McArdle (1940) as a useful means of differentiating hepatic from post-hepatic jaundice. He found low enzyme activity in jaundice of hepatic origin, and his observations have since been confirmed by others (Alcalde, 1950; Vorhaus, Scudamore, and Kark, 1950; Mann, Mandel, Eichman, Knowlton, and Sborov, 1952; Wilson, Calvert, and Geoghegan, 1952; Kaufman, 1954). Most workers have reported unimpaired $\mathrm{ChE}$ activity in post-hepatic jaundice.

The expectation that $\mathrm{ChE}$ activity would prove a useful test in the differential diagnosis of jaundice was not realized, mainly because of the difficult techniques involved in the early biological and chemical methods of assay. Final agreement has thus not yet been reached on the diagnostic value of ChE.

\section{Method}

A slight modification of the electrometric method described by Michel (1949) has been used in this study. In this method, which is simple and accurate, ChE activity is measured indirectly. The principle of the method is that $\mathrm{ChE}$ in serum hydrolyses a buffered solution of acetylcholine bromide, and the level of $\mathrm{ChE}$ is estimated indirectly by the amount of acetic acid produced. This is measured by the change in $\mathrm{pH}$ which occurs in an assay tube over a definite period of time during which a known volume of serum is incubated with an excess of substrate. The results are expressed in delta $p \mathrm{H}$ units per hour. The reagents used were as described by Michel (1949).

\section{Procedure}

Serum is obtained by centrifuging a specimen of clotted blood collected in a chemically-clean test tube. If the red blood corpuscles and serum are not separated, haemolysis occurs, and falsely high levels of ChE are obtained, as the $\mathrm{ChE}$ of corpuscles is present at a higher concentration than the ChE of serum (Callaway, Davies, and Rutland, 1951). The serum is frozen and preserved at $-15^{\circ} \mathrm{C}$. for a period of up to five days, if the estimation cannot be carried out immediately. The enzyme does not alter its activity during this time. (Molander, Friedman, and La Due (1954) showed that frozen sera gave reproducible results at monthly intervals over a period of several months.)

Freshly prepared working buffer at $p \mathrm{H} 8.00,40 \mathrm{ml}$., is added to a test tube in a water-bath at $25^{\circ} \mathrm{C}$., and allowed to equilibrate for 10 minutes. After preincubation at $25^{\circ} \mathrm{C}$. for the same time $4 \mathrm{ml}$. of acetyl choline bromide is added. Finally, $0.4 \mathrm{ml}$. of serum is added, the solution mixed in the tube, which is now stoppered, and the time noted. Incubation is carried out for one hour at $25^{\circ} \mathrm{C} . \pm 1^{\circ} \mathrm{C}$. It is quite essential for the temperature in the water-bath to remain constant at $25^{\circ} \mathrm{C} . \pm 1^{\circ} \mathrm{C}$. during the incubation period, otherwise the reaction velocity alters sufficiently to invalidate any results. The reaction is then stopped by placing the tube in an ice-bath. The final $p \mathrm{H}$ of the assay solution is read 
and compared with the $p \mathrm{H}$ of a control which does not contain serum. The difference represents the drop in $p \mathrm{H}$ due to the production of acetic acid by enzymatic hydrolysis. The use of a control for each set of estimations allows for the calculation of the small but definite amount of non-enzymatic hydrolysis which usually occurs.

Michel has given a table of factors to correct for the effect of a varying $p \mathrm{H}$ on the specific activity of ChE. When detailed investigations of small differences in $\mathrm{ChE}$ activity are being studied, this factor is employed. However, as it is insignificant, it is not used when ChE is being used as a test of liver function as only gross alteration from the normal is important in these circumstances.

\section{ReLiability OF THE METHOD}

In a consecutive series of $231 \mathrm{ChE}$ estimations carried out in duplicate, both assay tubes gave identical readings in $32.4 \%$, a difference of $0.02 p \mathrm{H}$ unit in $52.8 \%$, and a difference of $0.04 p \mathrm{H}$ unit in $14.6 \%$.

\section{RESULTS}

Serum Cholinesterase Activity in Healthy ADULTS.-ChE activity was measured in 50 healthy adult blood donors. The distribution of values is shown in Fig. 1. The observed range lay between 0.46 and 1.37 delta $p \mathrm{H}$ units per hour, with a mean value of 0.95 and standard deviation of \pm 0.20 . The normal range was considered to be $0.95 \pm 0.40$ $(0.55 \rightarrow 1 \cdot 35)$ delta $p \mathrm{H}$ units/hr. These values are very similar to those reported by Vorhaus et al. (1950), who reported a mean of 0.94 , a standard deviation of 0.16 , and a normal range of 0.68 to 1.37. Other workers have reported mean normal values for serum or plasma ranging from 0.703 (Michel, 1949) to 1.11 (Aldridge and Davies, 1952).

An implication of the wide range of normality is

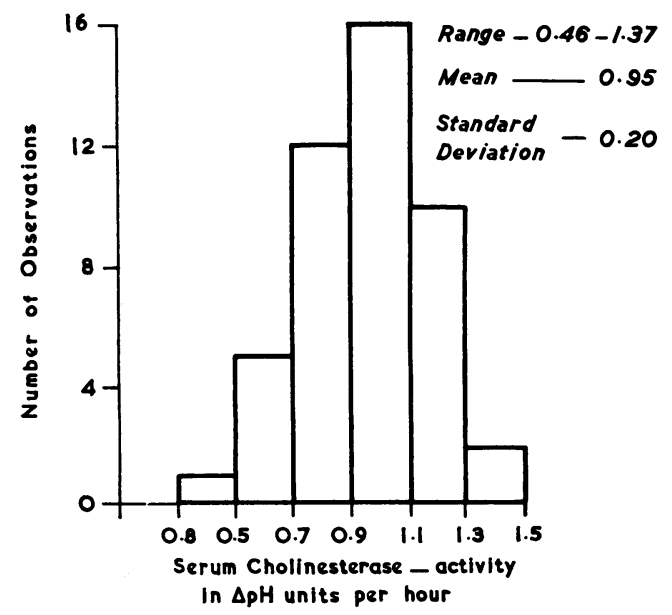

FIG. 1.-Range of serum cholinesterase activity in 50 healthy adult blood donors. that care is required in interpreting a single reading in a patient unless it is clearly beyond the normal range. A value may be within the normal range and yet be abnormal for the patient being studied.

Constancy of Serum Cholinesterase IN THE INDIVIDUAL.- The level of activity of $\mathrm{ChE}$ in eight hospital patients over a period of 15 days was studied, in order to determine the constancy or otherwise of the level in the individual subject. None of these patients had liver disease, or was being subjected to any drug therapy or operation which might have affected the results.

The results show a remarkable constancy in each individual over the period of 15 days (Table I). On

TABLE I

CHOLINESTERASE ACTIVITY (DELTA $p$ H UNITS/HR.) OVER 15 DAYS IN PATIENTS WITH NO LIVER DISEASE

\begin{tabular}{c|c|c|c|c|c|c|c}
\hline \multirow{3}{*}{ Patient } & \multicolumn{7}{|c}{ Day of Observation } \\
& \multicolumn{1}{|c|}{1} & 3 & 6 & 8 & 10 & 13 & 15 \\
\hline 1 & 0.82 & 0.94 & 0.80 & 0.84 & 0.90 & - & - \\
2 & 0.99 & 1.14 & 0.89 & 0.96 & 1.00 & 1.10 & 1.06 \\
3 & 0.94 & 1.03 & 0.87 & 0.89 & 0.84 & 0.98 & 0.93 \\
4 & 0.64 & 0.80 & 0.61 & 0.72 & 0.62 & 0.63 & 0.60 \\
5 & 0.87 & 1.08 & 0.92 & 0.91 & 0.92 & 0.97 & 0.91 \\
6 & 0.57 & 0.69 & 0.61 & 0.68 & 0.62 & 0.59 & 0.65 \\
7 & 1.04 & 1.13 & 0.99 & 0.99 & 0.94 & 0.93 & 0.91 \\
8 & 0.89 & 0.99 & 0.90 & 0.96 & 0.84 & 0.97 & 0.92 \\
\hline
\end{tabular}

only one day, the third, was there any significant difference between initial and subsequent values. This difference was common to all patients and was due to an instability of the $p \mathrm{H}$ meter on that day. It seems, therefore, that each individual has his own particular level of $\mathrm{ChE}$ which remains fairly constant. In one patient (No. 4) the level was held at a value near the lowest range of normality.

Alteration in Serum Cholinesterase Activity by Factors other than Hepato-Biliary Disease

EFFECT OF ANAESTHESIA AND OPERATION.-A study was made of alterations in ChE activity which occurred after operation. Similar observations on a number of other liver function tests were carried out at the same time for comparison. Thirty-four of the operations were considered major and 16 minor. No attempt was made to influence the choice of anaesthesia in current use. Blood samples were obtained for analysis for ChE before and after operation, on the morning of the first post-operative day, and every second morning thereafter for 14 days.

The mean $\mathrm{ChE}$ values for all 50 cases on the various days of estimation are shown in Fig. 2. There was an insignificant drop from 0.94 to 0.90 during the operation. A fall occurred in the days immediately after operation, the lowest value being 
reached on the fifth post-operative day. This fall was statistically significant $(\mathrm{P}<0 \cdot 1)$. By the thirteenth day this value had not increased, and so was still significantly below the original mean value. This drop in ChE activity occurred after both major and minor operations. In all, 31 cases out of 50 showed a fall of ChE greater than $30 \%$ of the initial value. There was no correlation between the percentage fall in $\mathrm{ChE}$ and the type or duration of the operation, the anaesthetic agents used, or the blood loss. An increased output of urinary urobilinogen was observed at the time of the fall in $\mathrm{ChE}$ and low values of $\mathrm{ChE}$ were associated with the development of a positive cephalin cholesterol flocculation.

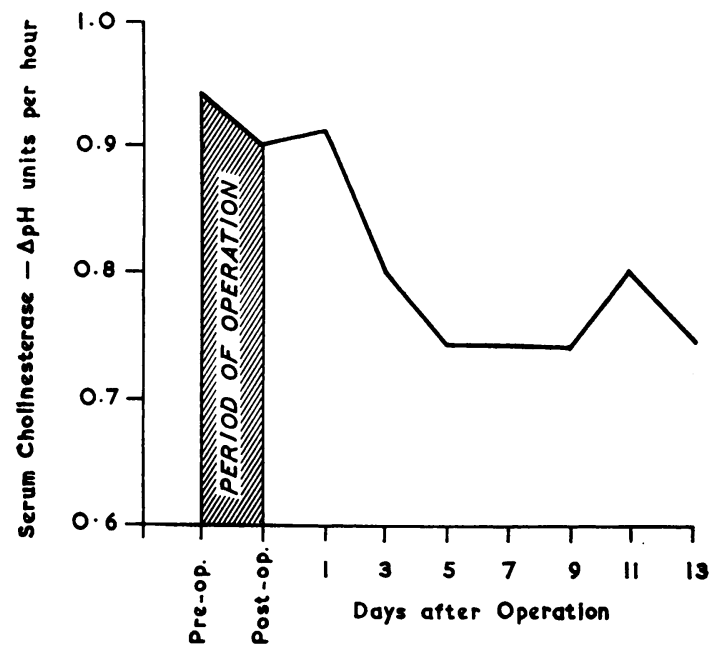

FIG. 2.-Changes in serum cholinesterase activity during and after operation (mean values for 50 patients).

Effect of Trauma.-Serial observations of ChE activity were carried out in patients who had sustained a fracture of the femur. Estimations were made on admission and weekly thereafter for eight to 10 weeks in seven patients. In six out of seven, a fall occurred in the first week, followed by a gradual rise over the ensuing weeks until the level had reached or even surpassed the original figure. In each patient, the level on admission to hospital, a few hours after the fracture was sustained, was considered the normal value for that individual patient.

The course followed by three patients is shown in Fig. 3. Case 1 shows the normal pattern which was observed. A fall is evident one week after injury, followed by a steady rise to normal level as the fracture healed with no complications. In Case II, the initial fall was followed by two further falls which were directly related in time to the occurrence of pneumonia, and subsequently to the

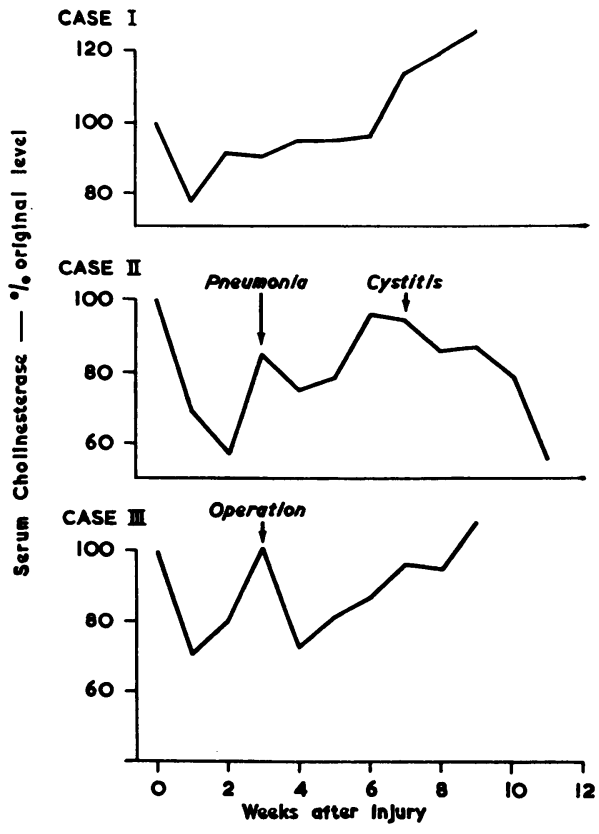

FIG. 3.-Serum cholinesterase activity in three patients after fracture of the femur.

development of a severe cystitis and ascending urinary infection which led to the patient's death. Case III shows two falls, the first in the period immediately after fracture, the second during the first week after pinning of the fractured neck of femur. This second fall corresponds to the postoperative changes described above.

EFFECT OF $x$-RAY THERAPY.-The effect on the level of circulating $\mathrm{ChE}$ was studied in a series of 12 patients who were being treated by $x$-ray therapy after mastectomy. The results are summarized in Table II, which also gives the dosage of deep therapy

TABLE II

SERUM CHOLINESTERASE LEVELS DURING COURSE OF $X$-RAY THERAPY AFTER MASTECTOMY FOR CARCINOMA OF BREAST

\begin{tabular}{|c|c|c|c|c|}
\hline Case No. & $\begin{array}{c}\text { Breast } \\
\text { Treated } \\
\text { (L or R) }\end{array}$ & $\begin{array}{c}\text { Maximum } \\
\text { ChE } \\
\text { Fall } \\
(\%)\end{array}$ & $\begin{array}{c}\text { Day } \\
\text { of } \\
\text { Maximum } \\
\text { Fall }\end{array}$ & $\begin{array}{c}\text { Symptoms } \\
\text { of } \\
\text { Radiation } \\
\text { Sickness }\end{array}$ \\
\hline $\begin{array}{r}1 \\
2 \\
3 \\
4 \\
5 \\
6 \\
7 \\
8 \\
9 \\
10 \\
11 \\
12\end{array}$ & $\begin{array}{l}\mathbf{L} \\
\mathbf{L} \\
\mathbf{R} \\
\mathbf{R} \\
\mathbf{R} \\
\mathbf{L} \\
\mathbf{L} \\
\mathbf{R} \\
\mathbf{L} \\
\mathbf{L} \\
\mathbf{R} \\
\mathbf{R}\end{array}$ & $\begin{array}{r}31 \\
22 \\
15 \\
0 \\
27 \\
37 \\
32 \\
45 \\
30 \\
0 \\
0 \\
10\end{array}$ & $\begin{array}{r}16 \\
9 \\
11 \\
12 \\
16 \\
16 \\
17 \\
9 \\
15\end{array}$ & $\begin{array}{r}0 \\
+++ \\
++ \\
0 \\
+++ \\
+ \\
+++ \\
+++ \\
++ \\
+ \\
+ \\
+\end{array}$ \\
\hline
\end{tabular}

Dosage: 3,750 r. central axis dosage to axilla $3,750 \longrightarrow 4,274$ r. glancing fields to chest. 


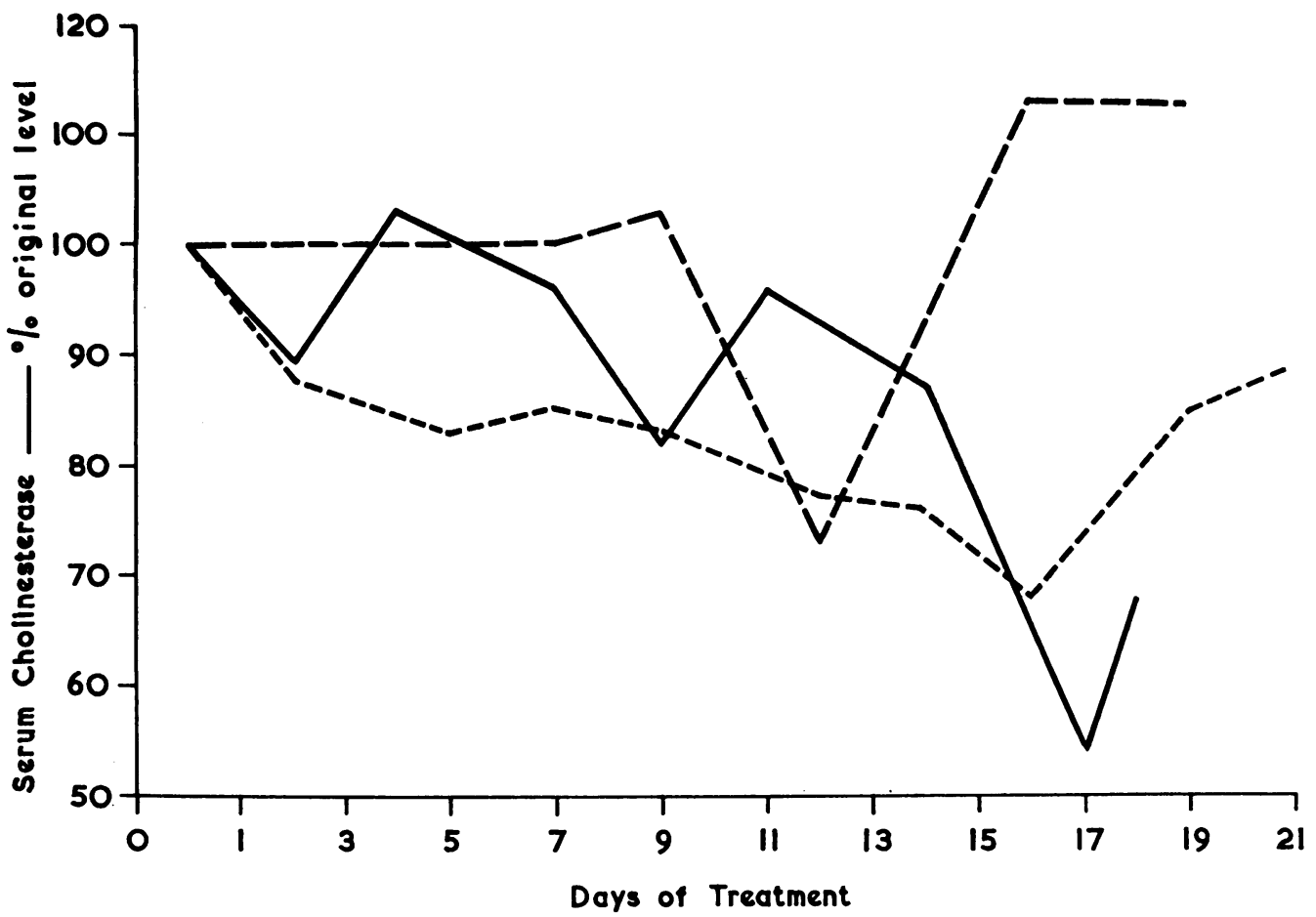

FIG. 4.-Alterations in serum cholinesterase activity in three patients undergoing $\mathrm{x}$-ray therapy after mastectomy for carcinoma of the breast.

used. However, the observed effects on ChE presumably reflect the "integral rate" which will have varied with the physical size of each patient. A fall in $\mathrm{ChE}$ was found in nine of the 12 patients. Typical examples of this are shown in Fig. 4. Very little change occurred during the first week, but $\mathrm{ChE}$ fell obviously during the second and third week. In each individual, there was a striking correlation in time between a fall in $\mathrm{ChE}$ and the occurrence of nausea and vomiting.

The Acute Abdomen.- ChE was estimated in a series of cases admitted with acute abdominal pain to a surgical ward. Blood was obtained from a vein shortly after the patient's admission and before the administration of any drug. After separation of the serum, it was kept at $-15^{\circ} \mathrm{C}$. until the estimation was carried out at a convenient time during the next 24 hours. In acute appendicitis, 50 observations were made and most of these lie within the normal range. Only four were found just below the lower limit of normal. It is of interest that three of those four patients had experienced symptoms over a period of some days and had developed an appendicular abscess. A further three patients with appendicular abscess had ChE levels of activity near the lower limit of normal. Thirteen cases of perforated duodenal ulcer were studied and showed a scattered distribution within the normal range. There was no correlation between the degree of peritoneal contamination and the level of $\mathrm{ChE}$ activity. In 18 cases of intestinal obstruction, there was again a scattered distribution of levels of activity. Particularly low values were found in two cases. A level of $\mathbf{0 . 3 2}$ was found in a patient with intestinal obstruction and strangulation, and one of 0.38 in a patient who had very extensive mesenteric thrombosis with gangrenous change in a large portion of the intestine. A scattergram of the above results is shown in Fig. 5, which also includes a comparison with $\mathrm{ChE}$ levels in 10 patients with chronic infection in whom the ChE level tended to be low. The six points on the scattergram representing the patients with appendicular abscess have been ringed for comparison with the other cases of appendicitis of short duration and the 10 cases of chronic sepsis.

Acute Pancreatitis.-Observations were made in 11 cases of acute pancreatitis. The value of ChE on admission was normal in every case. However, it fell dramatically in three patients 


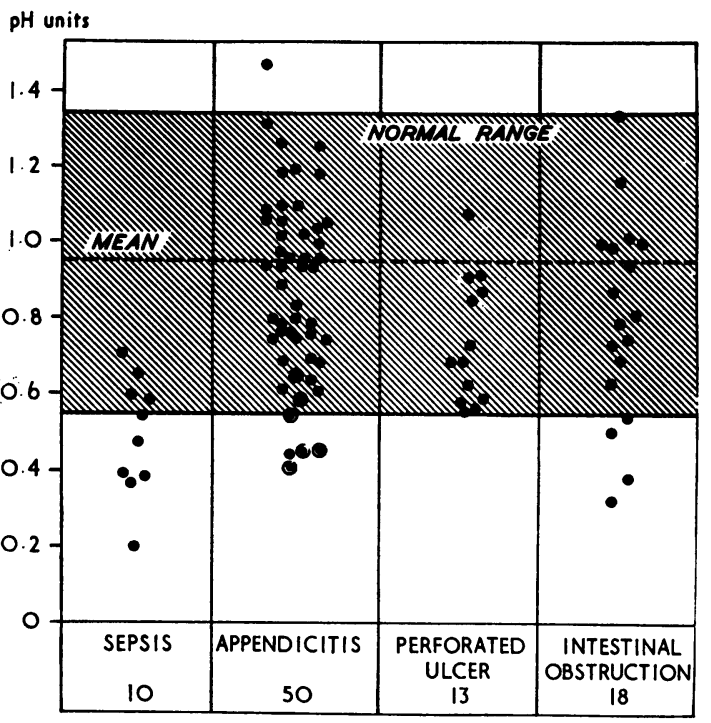

FIG. 5.-Serum cholinesterase activity in chronic sepsis and acute abdominal disease. Each point represents one patient, and the six ringed points indicate patients with appendicular abscess.

in whom serious clinical deterioration occurred.

A man, aged 46, presented with severe abdominal pain of 12 hours' duration. The abdominal wall was as rigid as a board, and a diagnosis of perforated peptic ulcer was made. At operation a haemorrhagic pancreatitis was found. Serum amylase on admission was 3,200 Somogyi units. The ChE level on the day of admission was 0.83 . By the following day it had fallen by more than $50 \%$ to 0.40 .

This patient, a woman aged 51, had a 12 hours' history of severe abdominal pain of sudden onset, radiating through to the back and associated with much nausea and vomiting. A diagnosis of acute pancreatitis was made, the serum amylase on admission being 3,200 Somogyi units. No operation was carried out. The ChE level on admission was 0.90 but had fallen by the next day to the very low level of $0 \cdot 15$. This patient subsequently died. Post-mortem examination showed that a haemorrhagic pancreatitis had completely destroyed the pancreas.

A woman, aged 59, was admitted following a six hours' history of severe abdominal pain of sudden onset accompanied by much nausea. Serum amylase on admission was 2,560 Somogyi units, and laparotomy confirmed the presence of haemorrhagic pancreatitis. The ChE level on admission was 0.90. This fell gradually in the course of the next three days to 0.65 and finally on the 24th day of a severe illness, complicated by a pancreatic fistula and pleural effusion, the value had dropped to $0 \cdot 16$.

Effect of Prolonged Infection.-The effect of prolonged infection on ChE activity was studied in 10 cases. These included such conditions as perinephric abscess, peridiverticular abscess, cellulitis of the leg, and pancreatic abscess. All infections had been present for at least one week and usually much longer, and all were causing marked constitutional upset. The levels of $\mathrm{ChE}$ in this group are shown in Fig. 5 where they are compared with the results in acute abdominal conditions. In six of the patients with chronic sepsis, the ChE level was found to be below the lower limit of the normal range; in the remaining four it was in the lower range of normal. When comparison is made with appendicitis (Fig. 5) it is noticeable that cases of inflammation of short duration (the majority of this group) lie in the normal range. On the other hand, low values were consistently seen in appendicular abscess where infection had been present for a longer period of time corresponding to the period of infection in the group of patients with chronic sepsis.

\section{Cholinesterase Activity in Hepato-biliary DISEASE}

Chronic Cholecystitis.-Estimations were made on 26 patients on their admission to hospital for elective cholecystectomy. None were jaundiced. Levels of ChE activity ranged from 0.97 to 1.83 delta $p \mathrm{H}$ units $/ \mathrm{hr}$. The mean value was 1.35 (the highest value in the normal range). Ten patients out of $\mathbf{2 6}$ had a value above the limit of normal, and none were significantly below the normal mean. In no other conditions were high values regularly observed.

ACute Cholecystitis.-In acute cholecystitis, estimations were made on seven patients who were not jaundiced. The range of activity lay between 0.83 and 1.27 . The mean was 1.02 . In view of the fact that inflammation has been shown to be accompanied by lowered ChE activity, it is worthy of note that these values are lower than those given above for chronic cholecystitis, but the mean is still somewhat above the normal mean of 0.95.

Non-Malignant Disease of Liver.-In cirrhosis, ChE was found to be low, the range being from 0.06 up to the lower limit of normal with a mean of 0.31 in seven cases. A level of 0.97 was found in a patient with presumed cardiac cirrhosis. Normal levels were found in two patients with reticulosis and one who was suffering from chronic alcoholism.

Metastatic Carcinoma of Liver.-Twenty-four patients with metastatic deposits in the liver have been studied. The range of activity lay between 0.20 and 1.20 delta $p \mathrm{H}$ units $/ \mathrm{hr}$. The mean was 0.52 , a level below the lower limit of the observed normal range $(0.55)$. Seventeen patients $(70.8 \%)$ had levels of activity at or below this figure; only one was above the normal mean level of 0.95 . 
TABLE III

SERUM CHOLINESTERASE IN HEPATIC JAUNDICE

\begin{tabular}{|c|c|c|c|}
\hline Diagnosis & No. of Cases & $\begin{array}{l}\text { Range } \\
\text { (Delta } p H\end{array}$ & $\begin{array}{c}\text { Mean } \\
\text { its/hr.) }\end{array}$ \\
\hline $\begin{array}{l}\text { Cirrhosis } \\
\text { Hepatitis } \\
\text { Others }\end{array}$ & $\begin{array}{r}14 \\
7 \\
13\end{array}$ & $\begin{array}{l}0.03 \text { to } 0.57 \\
0.00 \text { to } 0.72 \\
0.15 \text { to } 1.26\end{array}$ & $\begin{array}{l}0.28 \\
0.44 \\
0.75\end{array}$ \\
\hline Total & 34 & - & 0.49 \\
\hline
\end{tabular}

HEPATIC JAUNDICE.-Studies were made on 34 patients with varying types of hepatocellular disease. The results are summarized in Table III. In 24 , the $\mathrm{ChE}$ level was below the lower limit of normal: in three others it was approximately at this level, a total of $79.4 \%$ of those examined. In viral hepatitis, ChE activity ranged from 0. to 0.53 in six out of seven patients. In this group, a considerable systemic upset was present. The seventh patient had a relatively mild hepatitis, and had a recorded ChE of 0.72 well within the normal range. In cirrhosis with jaundice, 13 out of 14 patients had ChE levels of less than normal activity; in some, only slight evidence of $\mathrm{ChE}$ activity was found. The results obtained in hepatitis and cirrhosis are given in Fig. 6 where they are compared with those obtained in patients with stone in the common bile duct and biliary tract carcinoma.

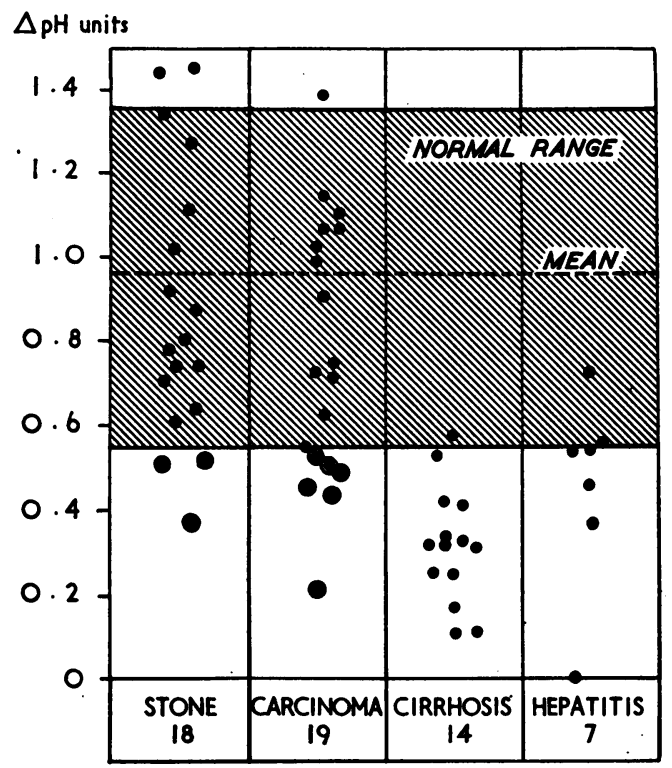

FIG. 6.-Serum cholinesterase activity in jaundice, comparing the levels in the principal causes of hepatic and post-hepatic jaundice. Each point represents one patient, and the ringed points a complication of posthepatic jaundice, namely, cholangitis, biliary cirrhosis, or metastases in the liver.
In general $\mathrm{ChE}$ activity mirrored the severity of the clinical condition. This is illustrated by the following two case histories. In the first patient, ChE activity was $0 \cdot 15$, an extremely low level. This patient, who had no previous history of illness, died shortly afterwards in hepatic coma from liver cell failure. The second patient, whose $\mathrm{ChE}$ was $1 \cdot 21$, high in the normal range, was a young man, aged 25, who was never acutely ill but had recurrent bouts of jaundice and tiredness. He was in all probability suffering from the cholangiolitic form of hepatitis.

In toxic hepatitis, the following results were obtained in three patients:-

\begin{tabular}{c|l|c}
\hline & & ChE \\
\hline 1 & Chlorpromazine jaundice & 1.14 \\
2 & Chronic mild carbon tetrachloride poisoning & 1.26 \\
3 & Nitrogen mustard therapy for metastatic carcinoma & 0.57 \\
\hline
\end{tabular}

The first two patients had only minor symptoms apart from jaundice and at no time did their condition give any cause for anxiety. The third patient developed jaundice following intravenous nitrogen mustard therapy for advanced carcinoma with hepatic metastases, so that the relatively low value might have resulted from the presence of these metastases.

Three cases of reticulosis were studied. One patient with lymphadenoma who survived had a ChE level of $1 \cdot 10$, while two whose ChE levels were 0.15 and 0.45 , died shortly afterwards from lymphadenoma and reticulosis.

Post-HEPATIC JAUNDICE.-Observations were made in 58 patients who had jaundice of posthepatic origin. The results are given in Table IV.

In most cases where cholelithiasis was associated with jaundice, ChE levels were normal or high. In these cases, jaundice was due to factors other than a stone in the duct, such as pressure from a swollen cystic gland or localized pancreatitis round the tip of the common duct. However, four patients had values less than the normal range: three had associated pancreatitis and the fourth had a pericholecystic abscess due to rupture of a necrotic gall bladder. When jaundice was due to stone in the

TABLE IV

CHOLINESTERASE IN POST-HEPATIC JAUNDICE

\begin{tabular}{l|c|c|c}
\hline \multicolumn{1}{c|}{ Diagnosis } & No. of Cases & $\begin{array}{c}\text { Range } \\
\text { (Delta } p H\end{array}$ & $\begin{array}{c}\text { Mean } \\
\text { units/hr.) }\end{array}$ \\
\hline $\begin{array}{l}\text { Cholelithiasis } \\
\begin{array}{c}\text { Stone in com- } \\
\text { mon bile duct }\end{array}\end{array}$ & 15 & 0.36 to 1.91 & 1.08 \\
$\begin{array}{l}\text { Biliary car- } \\
\text { cinoma }\end{array}$ & 18 & 0.37 to 1.45 & 0.88 \\
Others & 19 & $\begin{array}{l}0.21 \text { to } 1.38 \\
0.10 \text { to } 1.35\end{array}$ & 0.77 \\
\hline & 58 & - & 0.87 \\
\hline
\end{tabular}


common bile duct, only three out of 18 patients had ChE levels below normal: in two of these, biliary cirrhosis was also present and the third had the added complication of bronchopneumonia. In biliary tract carcinoma, only six out of 19 had levels under the normal range. There were complicating factors in all six: in three, hepatic metastases were present; in two, biliary cirrhosis had developed following long-standing obstruction; and the final case may have had hepatocellular damage from either syphilis or diabetes mellitus, both of which were present.

In the miscellaneous group of six cases of posthepatic jaundice, subnormal levels of $\mathrm{ChE}$ activity $(0.26$ and $0 \cdot 10)$ were observed in two patients with chronic infection, namely pancreatic abscess and subphrenic abscess.

In Fig. 6, the findings in biliary tract carcinoma and stone in the common bile duct are compared with these in 21 cases of hepatic jaundice due to cirrhosis or hepatitis. The cases with $\mathrm{ChE}$ levels under normal are ringed to show the presence of the complicating factors mentioned above.

\section{Prognostic Value of Cholinesterase in JAUNDICE}

In this series, ChE levels of under 0.55 delta $p H$ units/hr. were of grave significance in hepatic jaundice as $50 \%$ died in hospital. Five out of six patients with levels under 0.15 and nine out of 11 with levels under 0.35 died after brief illnesses. Of the remaining two patients, one had advanced cirrhosis with a gross ascites; the other patient, a young woman aged 26 , had a ChE activity of only 0.19 which subsequently fell to 0.03 before she finally died from a continuing chronic hepatitis. Five of the group underwent operation when the $\mathrm{ChE}$ activity was under $0 \cdot 5$. All five died in the postoperative period. In the similar group of patients with post-hepatic jaundice and a ChE level of under $0.55,11$ out of 15 survived.

\section{Relation to Level of Plasma Albumin in the Presence of Jaundice}

ChE activity has been related to the level of circulating plasma albumin in 67 jaundiced patients. In 12 patients where the albumin level lay between 2 and $3 \%$, the mean $\mathrm{ChE}$ was 0.53 , rising to 0.78 in 45 patients where the albumin was between 3 and $4 \%$. In 10 patients with plasma albumin over $4 \%$ the ChE mean was $\mathbf{0} \cdot 92$. In general, $\mathrm{ChE}$ activity followed the level of plasma albumin, low levels being found when the concentration of albumin was reduced and vice versa. However, there were many individual cases where there was no clear relation- ship. ChE activity was subnormal in seven out of 12 patients $(58 \%)$ whose plasma albumin was under $3 \%$ and in 21 out of $55(38 \%)$ in the group with albumin levels over $3 \%$.

The following points are worthy of note in the five cases where a normal $\mathrm{ChE}$ was associated with a plasma albumin level of under $3 \%$. In one case, ChE was at the lower level of normal. A fall may well have occurred from a more normal level as the patient's condition deteriorated with the development of jaundice complicating cirrhosis. In a further two cases, although apparently normal at the time of comparison with albumin, ChE activity had fallen by $52 \%$ in one case and in the other subsequently fell by $49 \%$, in both cases showing the reactivity of the test to infection. Only in two cases was there no apparent explanation for the low albumin level in conditions where the $\mathrm{ChE}$ would not be expected to be low. On the other hand, $\mathrm{ChE}$ was subnormal in 21 cases in the presence of albumin at a concentration over $3 \%$. In 11 of these cases a hepatic cause of the jaundice was present: in the remaining 10 where the jaundice was of post-hepatic origin there was in nine a reasonable explanation for the low ChE levels, namely, cholangitis, hepatic metastases, or secondary biliary cirrhosis.

Relation to Depth of Jaundice.-ChE activity has been compared with the depth of jaundice present in 79 patients, using serum bilirubin as an index of the intensity of jaundice. The results are summarized in Table V. ChE activity was found

TABLE V

RELATION BETWEEN SERUM CHOLINESTERASE AND SERUM BILIRUBIN

\begin{tabular}{c|c|c|c}
\hline No. of Patients & $\begin{array}{c}\text { Serum } \\
\text { Bilirubin } \\
\text { (mg. \%) }\end{array}$ & ChE Mean & Under Normal \\
\hline 57 & Under 10 & 0.83 & 38 \\
15 & $10-20$ & 0.69 & 53 \\
7 & Over 20 & $0 \cdot 25$ & 86 \\
\hline
\end{tabular}

to be low in those patients who were deeply jaundiced. This finding is of little diagnostic significance as the lesions responsible for the jaundice in patients with serum bilirubin levels over $10 \mathrm{mg} . \%$ were those which have been shown to be associated with low ChE activity without reference to the depth of jaundice (cirrhosis in relapse, biliary carcinoma with hepatic metastases, etc.).

\section{Discussion}

It has been shown that the level of ChE falls in a variety of circumstances not associated with a primary parenchymal lesion in the liver. It falls during the first week after trauma such as surgical 
operation or fracture of the femur, and also during $x$-ray therapy but is delayed until the second or third week. A fall has also been demonstrated in severe acute abdominal disease, when complicated by marked infection. Prolonged infection other than abdominal also leads to a fall. It has also been shown that although normal levels of ChE activity vary widely, each individual retains his own level under normal circumstances. On this basis the observed changes in conditions other than hepatic disease would appear to be significant, but there is no clear explantaion for their occurrence.

The post-operative results, considered alone, suggest that liver function is depressed postoperatively, most marked about the fifth day, and that $\mathrm{ChE}$ is a sensitive indicator. The positive cephalin cholesterol flocculation results add support to this, but were found only when complicating factors were present. A stronger support for the concept of hepatic injury is the finding of an increase in the output of urinary urobilinogen at the time that a fall in ChE activity was occurring. This was seen even in minor cases. A possible explanation is that hepatocellular injury was interfering with the destruction or re-excretion of urobilinogen absorbed from the intestine in the enterohepatic circulation.

$\mathrm{ChE}$ appears to originate in the liver and to be closely associated with the synthesis of serum albumin (Faber, 1943; Kunkel and Ward, 1947; Vorhaus and Kark, 1953). A fall, therefore, may be due to interference with this process in the liver cell. However, the observed post-operative fall may be related to several other factors: (1) Lack of essential amino-acids for its synthesis due to reduced intake in the post-operative phase; (2) loss of plasma protein by exudation at the site of operation, greater than can be currently replaced; (3) dilution of $\mathrm{ChE}$ in the circulating plasma during the period of fluid changes occurring in the extracellular space after operation.

In many of those cases which showed postoperative falls of $\mathrm{ChE}$, protein starvation was not a factor, as normal diet was resumed on the first post-operative day. Again, exudative loss at the operation site seems unlikely as operation was uncomplicated in many cases, a restricted site was involved, and post-operative progress was smooth. Dilution appears to be unlikely, as the levels fell post-operatively even after minor procedures.

Another factor of importance in the effect of trauma, operation, and infection on serum $\mathrm{ChE}$ levels is increased urinary nitrogen excretion. This may originate in increased catabolism which follows operation and is closely associated with operative trauma as suggested by Wilkinson, Billing, Nagy, and Stewart (1950). On the other hand, ingested protein may be used after injury to supply calories, the nitrogen content being excreted in the urine. Even though the post-operative caloric intake is apparently reasonable, it may not supply all needs. Armstrong (1957) has suggested that, for an average man, 4,000 calories may not be an excessive daily amount following major surgery. The combination of catabolism of body protein for caloric requirements with subsequent excretion of nitrogen could account for the drop in ChE after fracture, after operation, and in infection prolonged for any length of time. A significant change could be seen even in a week as ChE has been shown to have a life span of 28 days (Wescoe, Hunt, Riker, and Litt, 1947).

In the group of cases treated by $x$-ray therapy, the fall did not occur until significantly later-in the second or third week. In these patients, the hepatic area was included to some extent in the field of radiation, and hepatocellular damage due to the $x$ rays might be expected to result in the fall which was observed. Alternatively, the synthesis of $\mathrm{ChE}$ in the liver might have been impaired by some circulating product of cellular destruction. The lateness of the fall may have been due to the liberation into the blood stream of large amounts of $\mathrm{ChE}$ from the store in the liver parenchyma, thus concealing for an interval of one to two weeks the fall due to impaired synthesis of new ChE by the damaged cells. The association of a falling ChE with the symptoms of radiation sickness is of interest in view of the part possibly played by $\mathrm{ChE}$ in destroying cholinergic proteoses absorbed from the intestine and perhaps other sites (Barnard, 1952).

In other conditions, several factors may be involved. In haemorrhagic pancreatitis, for example, the observed fall in ChE activity may be the result of various influences in protein metabolism such as reduced intake of amino-acids, increased protein catabolism, and loss of protein by exudation into the site.

Whatever may be its value as an indicator of hepatocellular dysfunction, from the above considerations it appears that measurement of ChE activity can act as a general indicator of protein metabolism in the body. Under normal conditions the level remains constant. It falls in any condition, such as trauma, operation, or infection, which gives rise to increased catabolism; it rises subsequently to normal levels in the anabolic phase as in the healing stage of a fracture.

Estimation of ChE activity can be used as a liver function test in two different ways: as an index of liver function and as an aid in the differential diagnosis of jaundice. If a patient is known to have 
hepatic disease, $\mathrm{ChE}$ activity of less than the lower limit of normal ( 0.55 delta $p \mathrm{H}$ units/hr.) is indicative of serious disease. It follows that in conditions where hepatic disease is suspected, succinylcholine should not be given as a relaxant during anaesthesia unless the level of ChE is known, as $\mathrm{ChE}$ is responsible for the destruction of this substance. If the ChE level is under 0.35 the condition of the patient must be regarded as grave, and under no circumstances should he be subjected to operation. On the other hand, in jaundice due to biliary disease, low values of $\mathrm{ChE}$ do not carry the same grave prognosis, unless due to secondary carcinoma of the liver. In the remaining cases, low values are due to chronic infections such as cholangitis and pancreatic abscess, or to biliary cirrhosis without such other evidence of hepatocellular injury.

The low values seen in secondary carcinoma have been ascribed to cachexia, but Fremont-Smith, Volwiler, and Wood (1952) found a depression of $\mathrm{ChE}$ in the absence of cachexia. This is confirmed in the 24 cases in this investigation where cachexia was present only in the minority. Fremont-Smith and his co-workers found no difference between the mean value of $\mathrm{ChE}$ in patients cachectic from carcinoma, and the mean value in a series of patients suffering from extreme malnutrition due to other causes. It has been suggested that the low values in patients with liver metastases might be due to a local effect of the tumour on $\mathrm{ChE}$ formation by the liver cell (Williams, La Motta, and Wetstone, 1957). Another possible explanation is that the sheer bulk of the active tumour cells may utilize such a large amount of available nitrogenous material that the host is left with insufficient to continue with normal anabolic processes such as the formation of albumin and ChE (Terepka and Waterhouse, 1956).

The use of ChE activity as a test in the differential diagnosis of jaundice is limited by the response of the ChE to general metabolic changes, not necessarily associated with specific hepato-biliary disease. If some of the general factors previously discussed, such as chronic infection or operation, were to be introduced into a case of jaundice, great care would be required in interpretation of the ChE levels. An additional hazard is the development of secondary hepatic damage in patients who have a post-hepatic jaundice. It has been shown that secondary biliary cirrhosis due to chronic biliary tract obstruction and the presence of liver secondaries from biliary tract carcinoma will be associated with $\mathrm{ChE}$ activity of "hepatic levels". The diagnostic value of $\mathrm{ChE}$ is thus impaired to some extent. Nevertheless, levels under 0.35 have been found to be rare in post-hepatic jaundice unless obvious infection such as subphrenic abscess or pancreatic abscess is present. Measuring the activity of ChE should never be used by itself as a diagnostic test in jaundice. If used in combination with other tests which suggest hepatic disease, a low value will substantiate this. An extremely low value indicates a grave prognosis and operation should be avoided. A normal level, if borne out by clinical diagnosis and other function tests, will support the diagnosis of post-hepatic jaundice. If there is strong evidence that biliary tract carcinoma is present, a level under the lower limit of normal is an indication of secondary liver cell damage or of the presence of hepatic metastases.

I am grateful to Professor W. C. Wilson for his criticism, and for facilities for this study; also to the staff of the Department of Medical Illustration, Western Infirmary, Glasgow.

\section{REFERENCES}

Alcalde, J. M. O. (1950). "Serum cholinesterase determination in the differential diagnosis of jaundice". J. Lab. clin. Med., 36, 391.

Aldridge, W. N., and Davies, D. R. (1952). "Determination of cholinesterase activity in human blood". Brit. med. J., 1, 945.

Armstrong, S. H. (1957). In Physiologic Principles of Surgery, ed. Zimmerman, L. M., and Levine, R. Saunders, Philadelphia.

Barnard, R. D. (1952). "Therapeutic application of plasma cholinesterase". Lancet, 2, 1182.

Callaway, S., Davies, D. R., and Rutland, J. P. (1951). "Blood cholinesterase levels and range of personal variation in a healthy adult population". Brit. med. J., 2, 812 .

Faber, M. (1943). "The relationship between serum cholinesterase and serum albumin". Acta med. scand., 114, 72.

Fremont-Smith, K., Volwiler, W., and Wood, P. A. (1952). "Serum acetylcholinesterase. Its close correlation with serum albumin, and its limited usefulness as a test of liver function". J. Lab. clin. Med., 40, 692.

Kaufman, K. (1954). "Serum cholinesterase activity in the normal individual and in people with liver disease". Ann. intern. Med., individu.

Kunkel, H. G., and Ward, S. M. (1947). "Plasma esterase activity in patients with liver disease and the nephrotic syndrome". J. exp. Med., 86, 325.

McArdle, B. (1940). "The serum cholinesterase in jaundice and diseases of the liver". Quart. J. Med., 33, (n.s. 9), 107.

Mann, J. D., Mandel, W. I., Eichman, P. L., Knowlton, M. A., and Sborov, V. M. (1952). "Serum cholinesterase activity in liver disease". J. Lab. clin. Med., 39, 543.

Michel, H. O. (1949). "An electrometric method for the determination of red blood cell and plasma cholinesterase activity". Ibid., 34, 1564.

Molander, D. W., Friedman, M. M., and La Due, J. S. (1954). "Serum cholinesterase in hepatic and neoplastic diseases: a preliminary report". Ann. intern. Med., 41, 1139.

Terepka, A. R., and Waterhouse, C. (1956). "Metabolic observations during the forced feeding of patients with cancer". Amer. J. Med., 20, 225.

Vorhaus, L. J., and Kark, R. M. (1953). "Serum cholinesterase in health and disease". Ibid., 14, 707.

- Scudamore, H. H., and Kark, R. M. (1950). "Measurement of serum cholinesterase activity in the study of diseases of the liver and biliary system". Gastroenterology, 15, 304

Wescoe, W. C., Hunt, C. C., Riker, W. F., and Litt, I. C. (1947) "Regeneration rates of serum cholinesterase, in normal individuals and in patients with liver damage". Amer. J. Physiol., 149, 549.

Wilkinson A. W., Billing, B. H. Nagy, G., and Stewart, C. P. (1950) "Nitrogen metabolism after surgical operation". Use of a protein hydrolysate after partial gastrectomy". Lancet, 1, 533.

Williams, H. M., La Motta, R. V., and Wetstone, H. J. (1957). "Serum cholinesterase in obstructive jaundice and neoplastic disease". Gastroenterology, 33, 58.

Wilson, A., Calvert, R. J., and Geoghegan, H. (1952). "Plasma cholinesterase activity in liver disease: its value as a diagnostic test of liver function compared with flocculation tests and plasma protein determinations". J. clin. Invest., 31, 815. 